\title{
A floating-station structure
}

\author{
Henry RUFLI, Jakob SCHWANDER
}

\author{
Climate and Environmental Physics, Physics Institute, University of Bern, Sidlerstrasse 5, CH-3012 Bern, Switzerland \\ E-mail: rufli@climate.unibe.ch
}

\begin{abstract}
Long-term maintenance of camp constructions on snow and ice surfaces involves repeated adjustments of the vertical position of buildings due to snow accumulation or ice ablation. The principle of a low-effort vertical-adjustment station structure is presented. The basic idea is to construct a floatable spherical-shaped building that can be lifted by adding water underneath, which will then refreeze, or can be lowered by melting ice away from the base. Under cold polar conditions, the power requirement for melting the base free is approximately $100 \mathrm{~W} \mathrm{~m}^{-2}$ and is usually available as waste heat from the electric power generator of the station.
\end{abstract}

\section{INTRODUCTION AND CONCEPT}

Research or living facilities on snow or ice surfaces are normally exposed to precipitation of fresh snow, winddrifting snow, melting or sublimation. Long-term access and use of stations in such places are affected by these meteorological impacts. At most locations with perpetual snow or ice surfaces, like the ice sheets of Greenland and Antarctica and glaciers in alpine regions, there is no firm ground for long-term stations. In accumulation areas a building will eventually submerge. In ablation areas buildings end up on top of a pad like a 'glacier table'. The effort to maintain these buildings and keep them at surface level increases with every season of use.

We outline here a floating-station structure with a heatable base and water injection system, which can be maintained easily in a proper position relative to the surface. In an accumulation zone, injecting water under the station can be used to lift it. In an ablation zone, controlled melting of the ice layer under the station can be used to lower it.

For both procedures the bottom part of the station must be watertight and equipped with a heating system. For reasons explained later, a sphere-shaped construction offers the best performance. The sphere must be capable of floating on water, sinking under the surface up to one-third of its diameter. Generally, the immersion will be less than one-third, as the buoyancy of a $10 \mathrm{~m}$ spheroid dome immersed to one-third of its diameter, for example, is about $1300 \mathrm{kN}$, considerably more than the total weight anticipated for such a structure on ice. Before construction, a pit in the shape of the lower part of the station (an inverted spherical cap) has to be excavated in the snow or ice. For lifting the building, the pit must also be watertight; therefore, for a station on snow, a cover made of rubber or a strong liner is required.

The watertight bottom surface of the station is warmed, in order to melt it free from the ground, and is lowered by further heating. For raising the structure, water is injected between the pit surface and the outer shell of the building. After a lift of $10-15 \mathrm{~cm}$ the water is left to refreeze. Repeating this procedure will keep the building above ground for many years and reduces the effort of removing snowdrifts. At stations equipped with an electric power generator, the engine often supplies more heat than required to keep the inside of the building warm and for the water supply. This surplus heat could be used to melt drift snow and the water could be stored for the hydraulic lift.

\section{CONSTRUCTION FUNDAMENTALS}

The external shape of the station should be a complete sphere, realized for example with a geodesic dome design. Although this is not imperative for the hydraulic lifting discussed here, this particular shape has undoubted advantages. It has proved to perform well in wind-drifting snow. Independent of the wind direction, drift snow seldom covers the lee side of a sphere, in contrast to a square-shaped building or obstacle, where snow is accumulated by turbulence. For optimum operation it is important that the sphere has at least two-thirds of its diameter above the surface. Drift snow will keep clear around the building within a distance of up to one-third of the diameter until the drift snow reaches about half of the building height.

This behavior can be observed in nature. On a small scale, with wind-drifting snow or sand, roughly ball-shaped boulders lying on flat ground remain almost uncovered until the drifting material reaches a certain level. On a larger scale, rounded ice blocks or nunataks show the same effect. In addition, during summer, the dark surface radiates heat towards nearby drift snow which helps to keep the vicinity of the round obstacle free of snow.

Many dome structures used in the past have proved this positive performance (e.g. a test dome construction by PICO (Polar Ice Coring Office) at Dye 3, Greenland, after the deepdrilling GISP1 (Greenland Ice Sheet Project 1), dome constructions of different size at GRIP (Greenland Icecore Project; Gundestrup and others, 1994) and NorthGRIP, and the drill dome of GISP2I. A prerequisite is a sufficient distance between the buildings, a condition that was not fully satisfied at GRIP. However, the dome constructions at South Pole Station and the drill dome at GRIP are both too flat: only half of the sphere or less is above ground. In addition, the drill dome at GRIP was too close to the next building. Both became drifted in from the main wind direction.

On the other hand, square-shaped buildings like tents, and on a larger scale structures like the Dye 2 and Dye 3 stations in Greenland, which were placed on long columns, require extensive pushing of snow or need to be disassembled at the end of a field season and rebuilt for the next one or to be dragged on to a new pad from time to time. Constructions like the Dye 2 and Dye 3 stations, the new Armundsen-Scott South Pole Station, Dome Concordia, Anarctica, or smaller constructions like GISP2 station and Kohnen station, Anatarctica, have vertical legs based on a frame-like pad and can be jacked up mechanically or with 


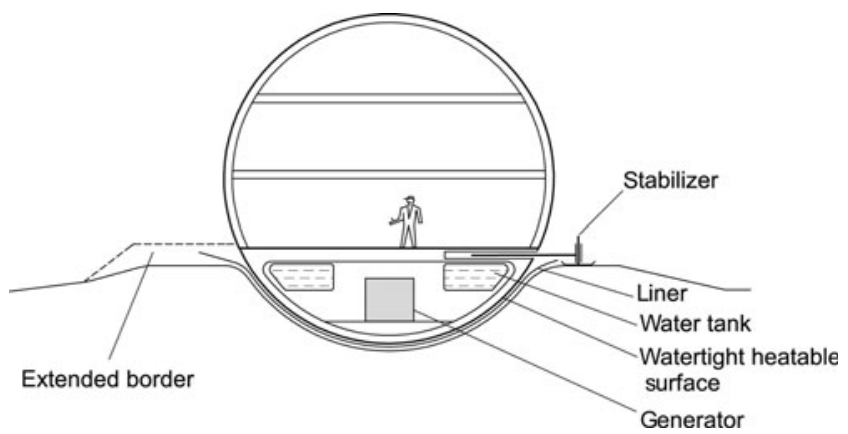

Fig. 1. Sketch of floating dome.

hydraulics. However, the columns can shift out of position and the lifting procedure then becomes more difficult. Although this problem can be overcome with retractable pillars, which can be underlaid with new snow one at a time, it is costly and requires very sturdy supporting structures. Such a design has been used for the FrenchItalian Concordia Station.

The advantage of the idea presented here is that there is no need for a steel base, which is usually abandoned after use. Instead, snow as a construction material is delivered freely by precipitation and wind. Another advantage of a spherical shape is the easy levelling in any direction without the need for extensive melting or addition of water.

\section{CONSTRUCTION GROUND}

\section{Snow or firn surface}

Depending on the condition and density of the snow surface and on the size of the construction, pre-compacting of the surface with vehicles, or cut and refill trenches with a snow blower, provide firmer ground for the set-up of the base (Lang and others, 1997). This procedure was used for the runway at the South Pole and on the side of the drill trench in NorthGRIP to support the roof. According to the expected weight and size of the building, the shape of the pit for the bottom part (segment of a sphere) has to be excavated in the prepared place. The snow that is removed can be used for a small dam around the pit. A watertight liner or rubber sheet is placed over this excavation to seal it. This cover should extend a certain distance over the border of the pit to allow a variable depth of immersion, depending on a certain tolerance of the total weight of the building, for the first lift. This way the border around the pit can be extended by packing a snow-water mix behind the liner. The liner may be covered with a thin layer of snow before placing the base on top, to avoid damage to the liner, and to compensate for small deviations between the shape of the pit and the base of the building. For subsequent lifting, the border around the pit will need to be built higher with a mix of snow and water. After a few lifts a thick layer of ice will be formed below the station, which will act as a watertight shell.

\section{Ice surface}

Only a shallow excavation is required to offer a pad area for the load. No liner is necessary. Warming the base surface will form a proper shape for the support and keep the support surface low. The building will not float and the load will squeeze the meltwater over the rim.

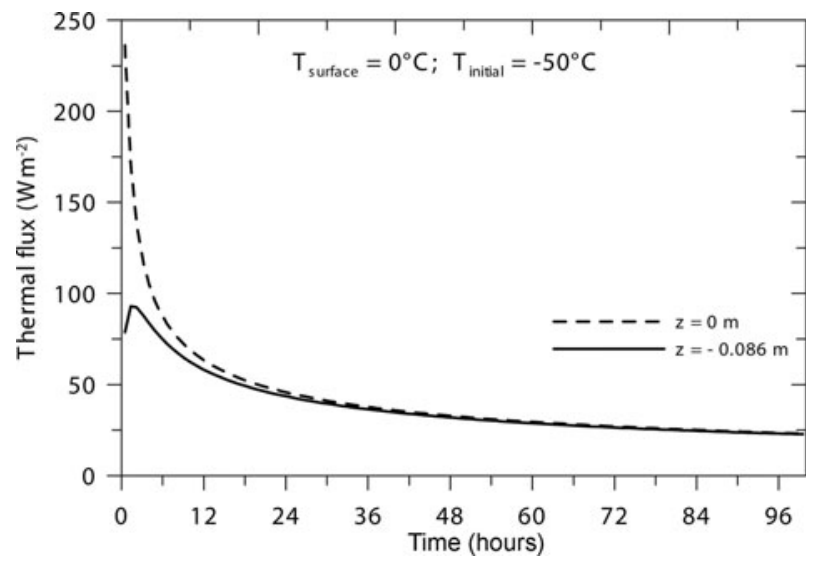

Fig. 2. Estimated power requirement for heating the firn surface to melting point. A simple one-dimensional model has been used to calculate the vertical thermal flux in firn, when maintaining the surface at the melting point at time $t>0$. The temperature for $t<0$ was set to $-50^{\circ} \mathrm{C}$. The thermal flux is shown for the surface $(z=0 \mathrm{~m})$ and at $0.086 \mathrm{~m}$ depth. The heat capacity of the building has been neglected. By integrating the surface flux we can estimate that, with a constant power of $100 \mathrm{~W} \mathrm{~m}^{-2}$, the surface reaches the melting point after approximately 18 hours.

\section{BUILDING DETAILS}

The intended use of the station will determine its size. Hydraulic lifting should work for any practical size of a dome. A dome diameter of 8-12 m could be a useful dimension; the actual size will also depend on commercially available dome designs. The geographic site of the station and hence the available transportation means have an important influence on the size of the parts. The framework and the shell can be prefabricated elements, similar to those used at GRIP and NorthGRIP or for the drill dome at GISP2. The sphere can be uniform in element design and material, or the lower one-third and upper twothirds can be made of different materials. The basement supports the building load on the surface of snow, ice and water, and its surface must be able to be heated to release it from the ground before a hydraulic jack-up with meltwater can begin. The preferred design is an aluminum framework with an aluminum shell for good heat transfer towards the ground. For the upper part above the basement, wooden elements are a lightweight option and show excellent behavior in dry and cold climates.

When the water that has been injected under the sphere for lifting freezes, the expansion of the ice can squeeze the building upwards. Selective heat control may help to refreeze the water from the bottom up and prevent damage to the structure by pressure build-up. The heating could be done with electric heater elements, facilitating uniform or differential warming of the surface. Another option is a pipe floorheating system with a closed circulation of antifreeze liquid. This could be used for warming as well as for fast cooling after lifting. An insulating cover over the heating elements directs the heat toward the outside, and in addition prevents melting of the ground by the regular station heating. A water storage tank can be placed in the basement to contain meltwater for the hydraulic lifting. This would also allow proper temperature conditioning of the water. Additionally, an injection system with a pump is required to transfer the water from the tank to the interface between pit and base. To 
prevent the sphere from free rotation in floating mode and to level the building while lifting, the basement also needs three legs around the outside in a $120^{\circ}$ angular displacement to each other. A jack in each leg allows adjustment during the lifting process. After refreezing, the legs should be retracted like landing gear, or removed to avoid turbulence and snowdrift close to the sphere. Alternatively, small structures could be stabilized with three ropes (Fig. 1).

On an ice surface in ablation areas the stabilizer legs have to be expandable to allow adjustment to the melting ice surface. The legs should be firmly attached to the building and may need to be strong enough to support the building.

\section{LIFTING THE BUILDING AND ENERGY REQUIREMENT}

Accumulation and wind drift are rather variable in polar regions, so the interval between lifts depends on precipitation and wind deposition. After the building is placed on top of the liner it will settle during the first season. In the following season a first lift of the station is possible. The estimated amount of meltwater has to be prepared and stored in the water tank. The base of the sphere must then be warmed up. Figure 2 shows an estimated thermal flux in the firn underneath when the interface is warmed up to the melting point. Under most circumstances it should be possible to bring the base to the melting point in less than 24 hours with a heating power of $100 \mathrm{~W} \mathrm{~m}^{-2}$. Then the water can be injected between the liner and the basement for floating and a hydraulic lift of about $10 \mathrm{~cm}$. By controlled switching of the surface heating of the base, the injected water will freeze from bottom to top. A timely lifting of the station will reduce the snowdrift with the benefit of requiring less frequent lifting.

\section{CONCLUSIONS}

An idea for maintaining a camp structure above snow under polar conditions has been presented. The main advantage is the effortless vertical adjustment of the building by pumping water underneath the impermeable base to lift it above snowdrift, or by melting ice at the base when used in an ablation zone. The construction does not require a sturdy platform underneath and, except for the pit liner, it can be completely retrograded after use. Compared with other solutions for large long-term stations using retractable pillars, the floating dome design is lightweight and inexpensive and could fill a gap for intermediate-size operations.

\section{REFERENCES}

Gundestrup, N.S., J.P. Steffensen and J. Schwander. 1994. The GRIP deep drilling camp. Nat. Inst. Polar Res. Mem., 49, Special Issue, 358-370.

Lang, R.M., G.L. Blaisdell, C. D'Urso, G. Reinemer and M. Lesher. 1997. Processing snow for high strength roads and runways. Cold Reg. Sci. Technol., 25(1), 17-31. 